\title{
FURTHER CONSIDERATION OF TWO PHOTOGRAPHS ASCRIBED TO CHRISTIAN HORNBERGER ${ }^{1}$
}

\author{
Paul Jenkins \\ Basel Mission Society
}

Thomas Theye
Bremen

I

Two reactions to the essay on the earliest generation of missionary photographers in West Africa published earlier in $H A$ set up trains of thought which deserve to be minuted here as a further contribution to our praxis with images of Africa in the nineteenth century. It was pointed out by two readers of the original article that a pair of the images which, it had been asserted (104), derive from the last phase of Hornberger's photographic work, were published very early on in a non-mission context: that of three women spinning and that of one man weaving (figures 1 and 2 below).

Both images exist as photographs, as stereographic vintage prints. Both were also published as wood engravings in mission periodicals (figures 3 and 4). Two readers of the original essay have pointed out that these images were conflated into a single engraving on page 211 of Richard Oberländer's Westafrika vom Senegal bis Benguela (Leipzig, 1874). In this image (figure 5), however, only two members of the group of spinning women are depicted, placed separately in the foreground, one on each side of the weaver. It is an ironic reflection on the quality of the documentation we have to fear in this field that Oberländer's caption - "Spinnende und webende Aschanti. (Nach einer Photographie)"- asserts specifically that the engraving was taken "from a photograph," using the singular form.

This reference to Oberländer provides a useful complement to the results reported in the original paper, based as this was almost exclusively on work in mission archives, especially those in Basel and Bremen. It is an excellent demonstration of one of the main assertions made there: that photographs were widely published as engravings before $\mathrm{ca}$. 1890 . How widely becomes apparent here: photographs taken by a missionary provide the basis for an illustration in a secular publication on Africa. In other words, the search for contemporary published visual sources on nineteenth-century Africa needs to be comprehensive in respect of the kinds of literature with which we concern ourselves.

The Oberländer engraving also illustrates the main problem engravings pose when regarded as quasi-photographical sources for African history in this

History in Africa, 22 (1995), 271-279. 


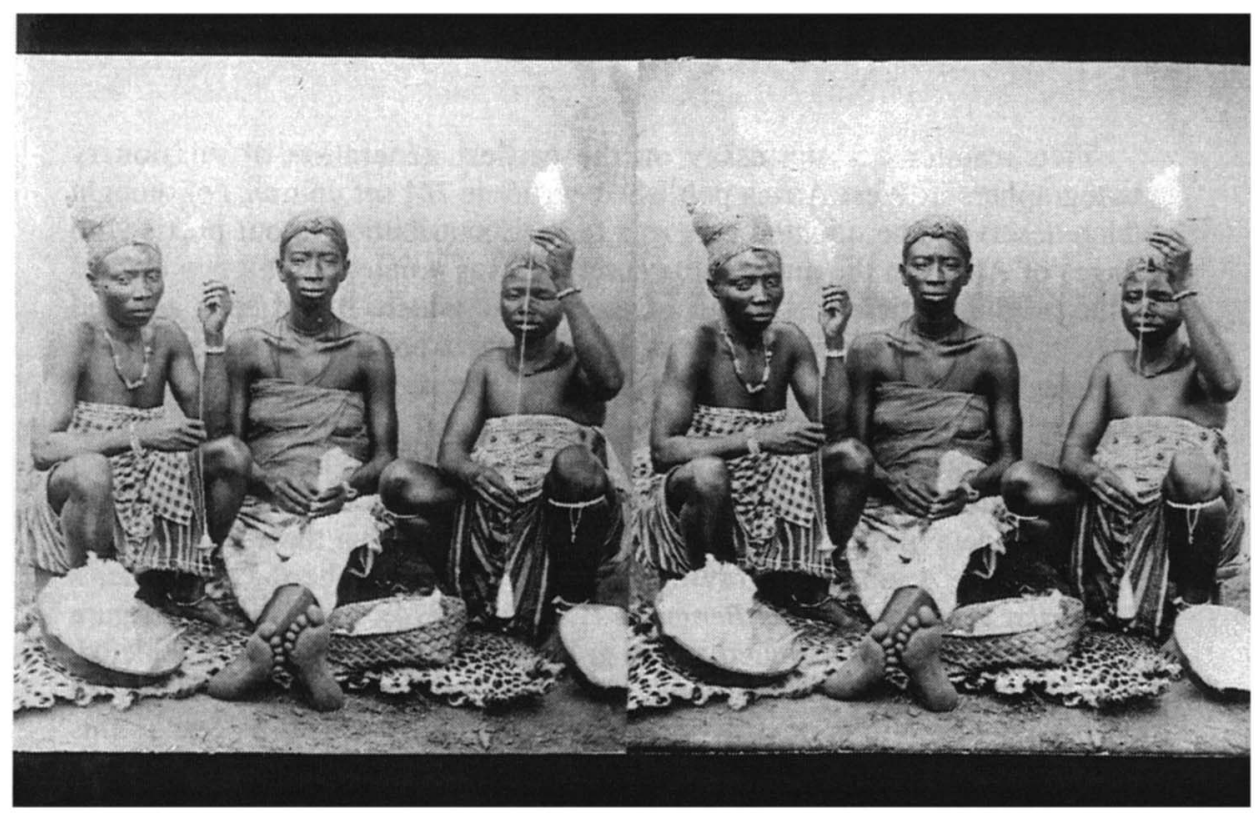

\section{Figure 1}

Reproduction of a stereoscopic vintage print of three women spinning cotton, very probably taken in the southern Volta Region of present-day Ghana by Christian Hornberger, member of the North German (Bremen) Missionary Society, in 1867-68. The Basel Mission vintage print is at QD-30.014.055. The two sides of the image, each measuring $8.2 \mathrm{~cm}$ (height) by $7.5 \mathrm{~cm}$, are pasted separately onto a cardboard backing which measures $8.2 \mathrm{~cm}$ by $17.7 \mathrm{~cm}$. 


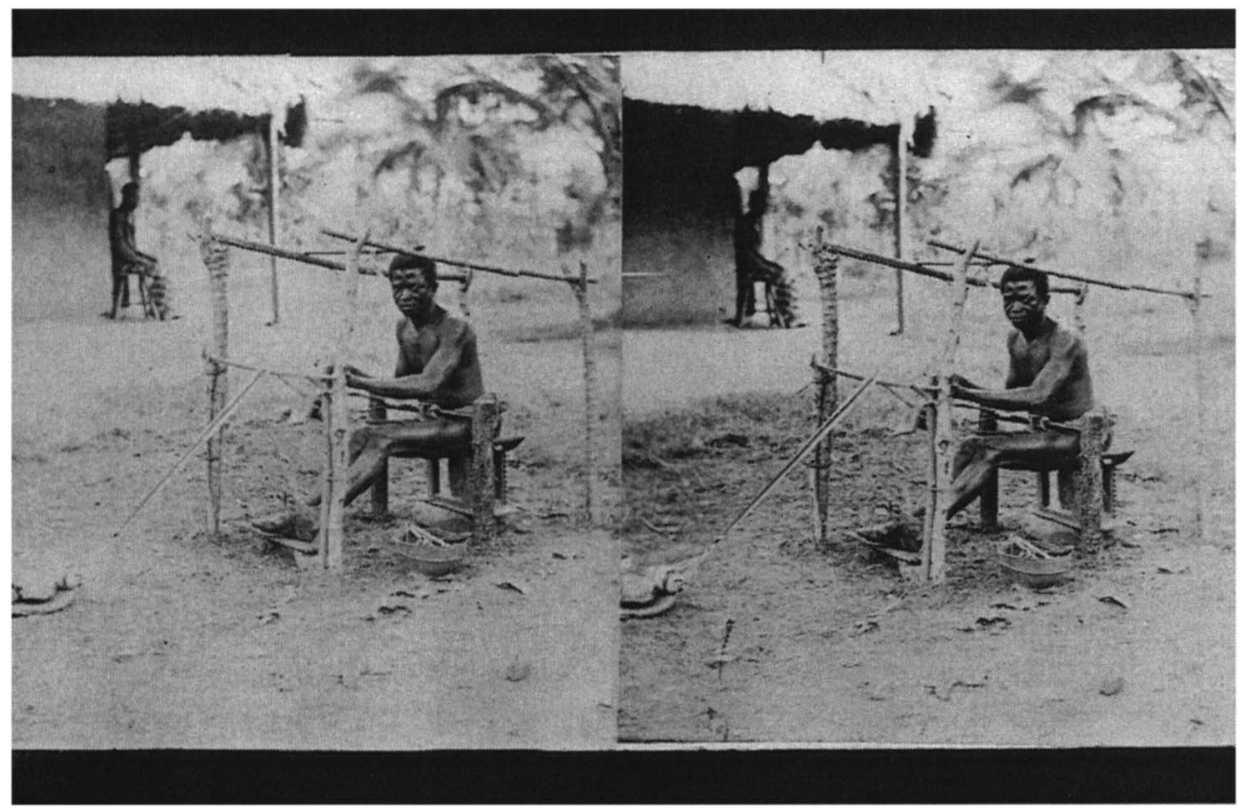

\section{Figure 2}

Reproduction of a stereoscopic vintage print of a weaver, taken in the southern Volta Region of present-day Ghana by Christian Hornberger, member of the North German (Bremen) Missionary Society, almost certainly in 1867-68. Basel Mission Archive QD30.014.056. Technical details as for Figure 1. 
period. The creation of an engraving was not merely a mechanical process. The hand - and mind - of one or more human artists or craftsmen intervened between the photograph and the printed page, and changes could be introduced into the originally photographic image, inspired by a wide range of editorial motivations. The two series comprising figures $1>3>5$ and figures $2>4>5$ show that, while engravings could be impressively accurate in their reproduction, they could also be very much products of a European or American atelier.

Developing sensitivity to this problem will be essential if we are to exploit the research possibilities such engravings offer. These must be very considerable indeed. The earlier essay referred to the large numbers of photographs probably published as engravings in missionary literature published between the beginning of missionary photography in Africa and $c a$. 1890 , when photogravure prints begin to appear in missionary periodicals. Referring to more general literature on the continent of Europe the point can be made still more strikingly. For virtually five decades, between Noël-Marie Payma Lerebours' Excursions Daguerriennes (Paris, 1841) and Nouvelles Excursions Daguerriennes (Paris, 1842) and Friedrich Ratzels' three-volume Völkerkunde (Leipzig, 1885-88) publishers wanting to use images from Africa as illustrations in their books and periodicals virtually had only the choice between either making individual photographic prints and attaching them to their products - a recipe for a very small print run-or transferring the images by hand into another medium. Of the various media on offer the wood engraving was by far the most commonly used, and one which made possible a relatively large print run. ${ }^{2}$

Oberländer also raises the question of captions as a source of substantive information on images. His caption to this engraving is not only faulty in respect of the source the engraver used, he also locates the spinners and the weaver in Asante, and not in the southern Volta Region of present-day Ghana, where Hornberger was doing his photography. This would not, perhaps, present a major difficulty were the documentation of these images entirely satisfactory otherwise. The ascription of the photograph of the weaver to Hornberger is not problematic - the Monatsblatt der Norddeutschen Mission unequivocally stated in 1885 that this image was derived from a Hornberger photograph taken in Ho. But the spinning ladies are much less welldocumented. The 1870 publication (figure 3 ) is merely entitled "Spinnende Negerfrauen in Westafrika" (black women spinning in West Africa). It was used to illustrate an article on women in wartime in southern Ghana, but there was no reference in the article to the illustration. And the essay on this image in Monatsblatt der Norddeutschen Mission (January 1885) can be taken at best to imply that the photograph was taken in Eweland-but the actual commentary is taken from a text written by a German member of the Church Missionary Society staff in Yorubaland. 


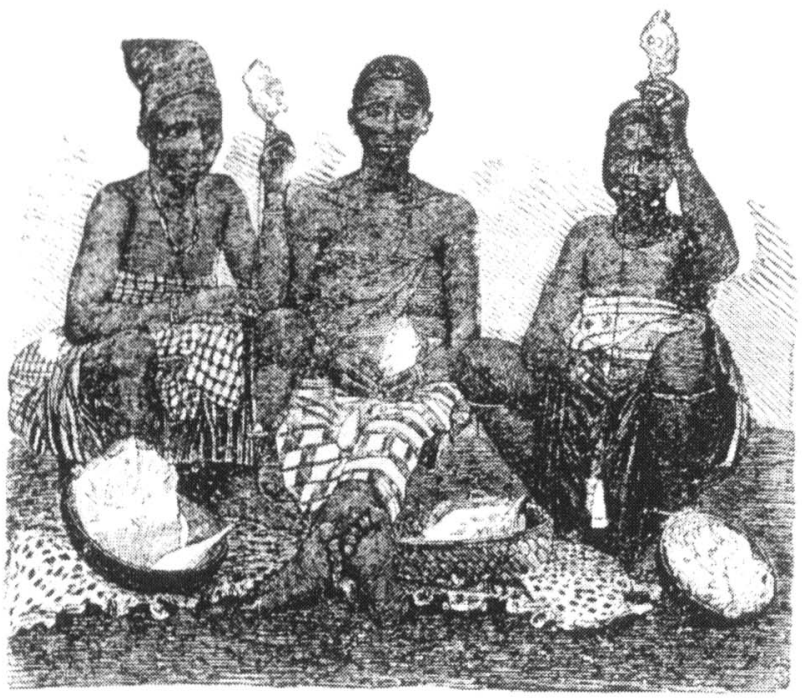

\section{Spinnende Żegerinnen von Zseftafrika.}

\section{Figure 3}

Engraving of the three women spinning cotton, published in the Basel Mission periodical Evangelischer Heidenbote (1870), 123.

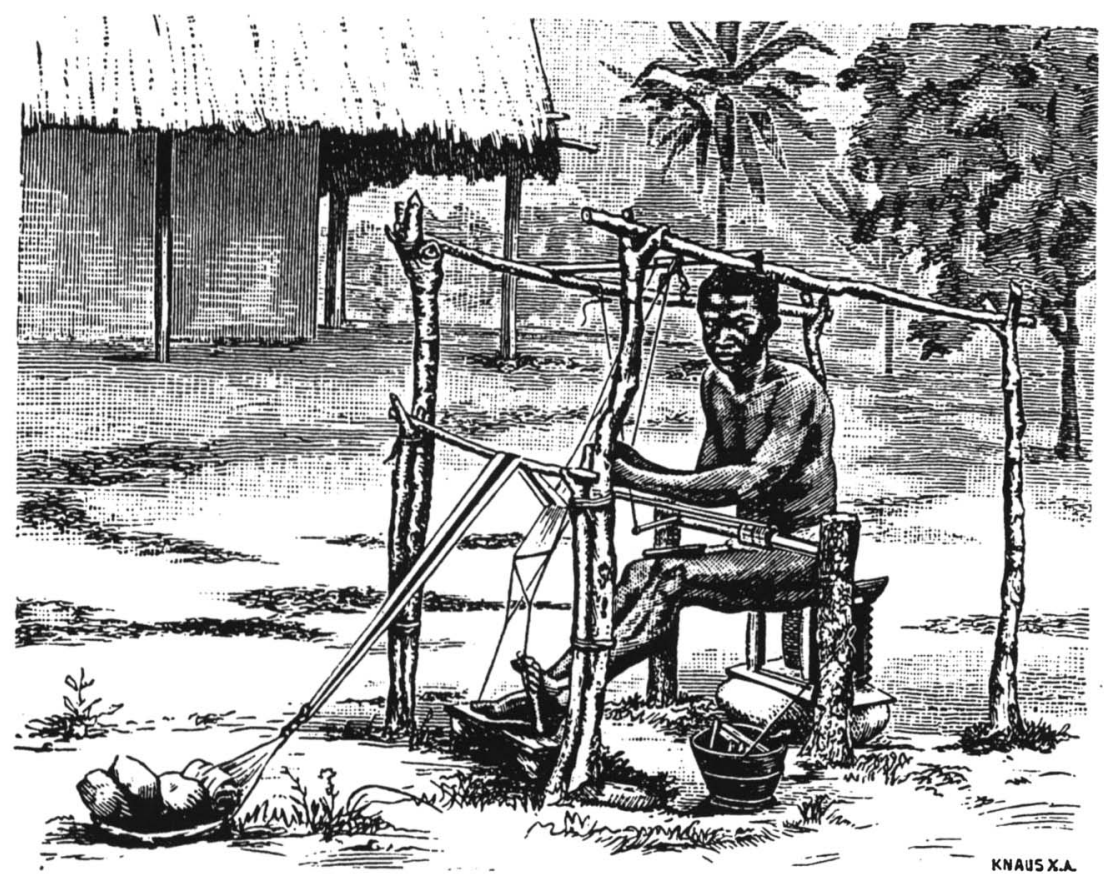

\section{Figure 4}

Engraving of the weaver, published in the North German Mission periodical Monatsblatt 
Is it possible, therefore, that this image was derived from a source other than Hornberger-a photograph taken somewhere other than the southern Volta Region of Ghana? It is certainly clear that missionary societies were supplying each other with images suitable for publication at this period (92), so that in principle a badly-documented image can have originated anywhere in Africa where missionaries had cameras or access to the productions of studios.

The problem is further complicated by a caption to a vintage print of the spinning women still held by an important Berlin collection. The Africa Department of the Berlin Museum für Völkerkunde possesses a vast collection of nineteenth-century photographs which originally belonged to the Berliner Gesellschaft für Anthropologie, Ethnologie und Urgeschichte. The Society was founded in 1869 by Adolf Bastian, Rudolf Virchow, and others, and established a photographic archive soon after. One of the old portfolios bears the title "No. 71, West- und Südwestafrika," and contains a page with an assortment of tipped-in photographs, including a full stereoscopic photographic print of the spinning women. There the handwritten caption reads "P.200. 'E'qba Weiber. Stereoskopische Aufnahme" (i.e., 'Eq'ba women. Stereoscopic photograph). Underneath someone has also written, in another hand, or at least with another pen, "Wegbe."

Being a handwritten caption, the spelling of proper names is not entirely clear-“"E'qba" could well read" 'E'gba"- and the coincidence of the possible title "Egba women" in Berlin with the Bremen Mission's published commentary in 1885 having been based on experience in Yorubaland led Thomas Theye to request a clarification as to the grounds on which this image of spinning women had been ascribed to Christian Hornberger in the $H A$ article, a point on which that essay could not discuss, but which it is useful to rehearse here, if only in outline.

In Basel the photograph of the women spinning occurs in a group of 12 stereo prints, all in the same anonymous album (ref. no. QD-30.014) which are identical to one another in all technical aspects (size, cardboard backing, and an unusual type of attachment to the album). It seems reasonable therefore, all other things being equal, to assume that these images came from a common source. The captions are all simply descriptive, and offer no information about the place where the image was taken or the name of the photographer.

There are, however, three reasons for ascribing this group of stereographic images to Hornberger and to no one else. Firstly, two of these images (the man weaving and a woman grinding corn) are clearly ascribed to Hornberger when they were published in the Monatsblatt der Norddeutschen Mission in 1885 and 1888 respectively. Secondly, a further image shows an unusual arrangment of indigenous pots (figures $4 a$ and $4 b$ ) which, although this is not specifically stated, is almost certainly the Hornberger photograph of pottery advertised for sale in the Monatsblatt in 1868 (100). These are strong indications to regard these stereoscopes as Hornberger's work - and we know that he was taking stereos as early as $1866(98)$. 


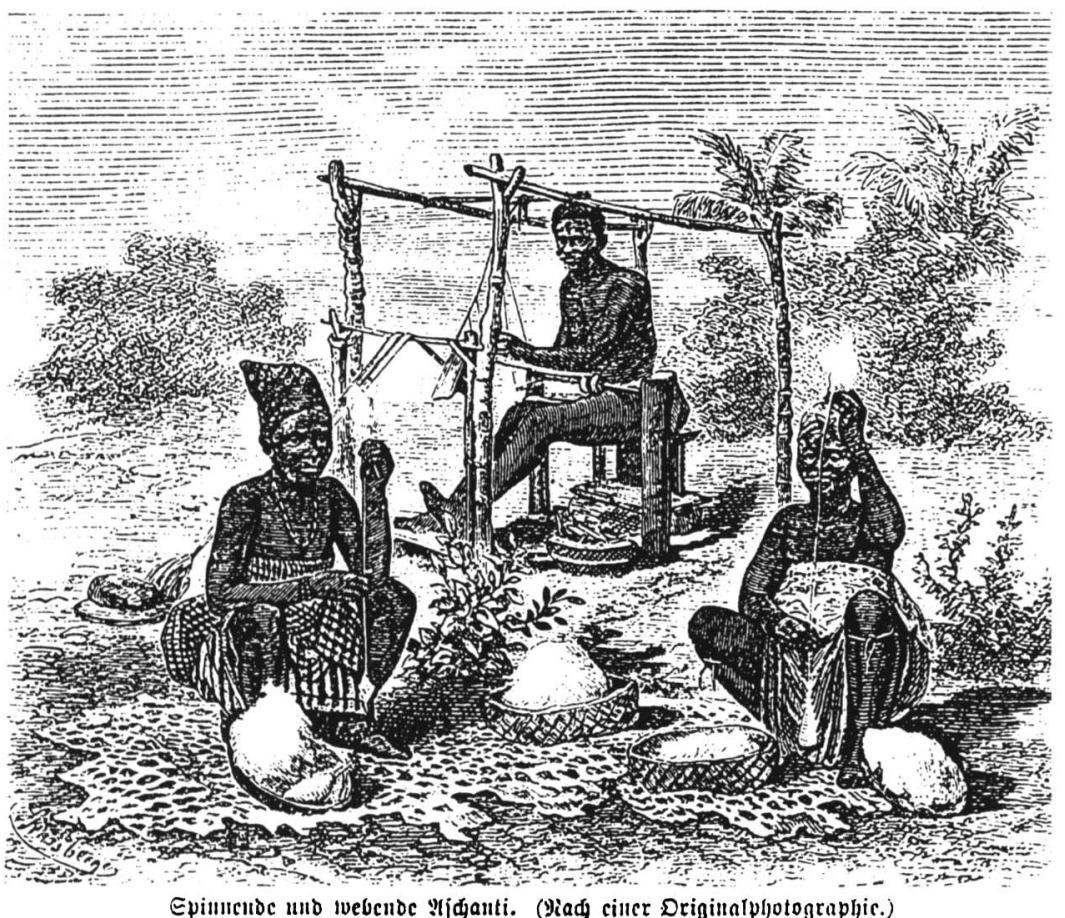

Figure 5

Composite publications of the two images as a single engraving in Richard Oberländer, Westafrika vom Senegal bis Benuela, 211 
But there is a third reason as well for linking these photographs with Hornberger. The album to which these stereos were attached contains about 60 images altogether which, with two exceptions only, are from Ghana. Many of them are evidently very early. Perhaps half the images have captions which locate them in the Basel Mission area of southern Ghana west of the Volta, where, as far as we know, Hornberger did not take photographs. Among those with no captions or only very general captions there is also a short series of portraits of women which seems to derive from a studio and can hardly be Hornberger's. The rest - stereos and single prints - can plausibly be ascribed to Hornberger, including, as the single prints do, the only examples in the Basel holdings of portraits of ex-slave children (98), and four images which can be identified quite clearly as deriving from Hornberger's photography in $\mathrm{Ho}$-one portrait of the ruler of Ho with one of his wives, one of the ruler of Ho's spokesman with a bodyguard (figure 3 ), and two of a figure who is described elsewhere as the chief fetish priest of Ho.

There are good reasons therefore for ascribing the photograph of the spinning women to Hornberger, and for arguing that the image belongs to the later phase of his photographic work. And, indeed, the most unambiguous, concrete, and plausible element in the Berlin caption-the reference to Wegbe-supports an ascription to Hornberger. Wegbe is the name of the quarter of Ho in which the North German Mission had its station in the 1860s and where Hornberger was resident for many years.

A further confirmation of the ascription to Hornberger, although it suggests another location for the image, comes from a publication by the Hamburg photographers Carl and Friedrich Wilhem Dammann. ${ }^{3}$ In the mid1870s they published two collections of photographic prints for classroom use in physical anthropology. Both include the image of the spinning women. The English version, Races of Mankind (London, [1876?]), offers only a general caption - "Plate XIV Niger District. Upper Guinea...Female Spinners." But the German version, Anthropologisches Schul-Album in Photographien (Berlin, [1876?]), offers the caption "Afrika. Tafel V. OberGuinea (Nigergebiet)...No. 29 Waya (Spinnerinnen)." Waya is another southern Ewe town in which the North German Mission worked in the 1860s, and a place where Hornberger is known to have taken photographs.

Since "Wegbe" may refer to the normal location of the photographer, one might prefer Waya as the actual location of the photograph..., but at any rate, the serious general scepticism which one needs to apply to the documentation of photographs should be able to yield here to the strong case which can be argued for asserting that this image is a Hornberger photograph.

\section{II}

As a contribution to our praxis with nineteenth-century images from Africa, this note has indicated that it is worth while collating the different published images which one can find widely scattered in the literature. with the holdings of museums and archives. Comparisons can assist us to sense the 
documentary quality of individual images as sources for African history, including historical anthropology. As well, discrepant captions, read critically, might offer at least some help with the historian's common despair, faced with a photograph which is potentially an important source but whose documentation is so faulty it does not answer the important questions we have to pose: when was this photograph taken? Where? By whom? Why? And whom or what does it depict?

\section{Notes}

1. This paper continues one of the points raised in Paul Jenkins, "The Earliest Missionary Photographers in West Africa and the Portrayal of Indigenous People and Culture," HA 20 (1993), 89-118. Page and figure numbers in paretheses refer to this article.

2. The crafts which produced the wood engravings published in newspapers, journals, and books in the nineteenth century have since fallen into disuse, much as traditional typesetting has. Proper modern research on procedures and workshops would be an important contribution to the history of the published image of Africa in the nineteenth century, as would an easily accessible account of other techniques used at the time for transferring photographs to the medium of book printing.

3. Thomas Theye is currently working on the anthropological oeuvre of the Dammanns. 